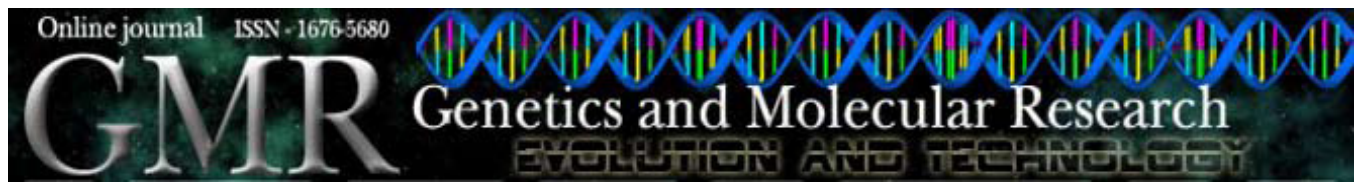

Case Report

\title{
Oropharyngeal dysphagia and language delay in partial trisomy 9p: case report
}

N.F. Rossi ${ }^{1}$, A.R. Gatto ${ }^{2}$, P.C. Cola ${ }^{3}$, D.H. Souza ${ }^{1}$, D. Moretti-Ferreira ${ }^{1}$ and C.M. Giacheti ${ }^{4}$

${ }^{1}$ Departamento de Genética, Instituto de Biociências de Botucatu, Universidade Estadual Paulista, Botucatu, SP, Brasil

${ }^{2}$ Departamento de Neurologia, Faculdade de Medicina de Botucatu, Universidade Estadual Paulista, Botucatu, SP, Brasil

${ }^{3}$ Departamento de Cirurgia, Faculdade de Medicina de Botucatu, Universidade Estadual Paulista, Botucatu, SP, Brasil

${ }^{4}$ Departamento de Fonoaudiologia, Faculdade de Filosofia e Ciências, Universidade Estadual Paulista, Marília, SP, Brasil

Corresponding author: D. Moretti-Ferreira

E-mail:sag@fmb.unesp.br

Genet. Mol. Res. 8 (3): 1133-1138 (2009)

Received April 3, 2009

Accepted April 13, 2009

Published September 22, 2009

No commercial party having a direct financial interest in the results of the research supporting this article has or will confer a benefit upon the authors or upon any organization with which the authors are associated.

ABSTRACT. The phenotype of partial trisomy $9 p$ includes global developmental delay, microcephaly, bulbous nose, downturned oral commissures, malformed ears, hypotonia, and severe cognitive and language disorders. We present a case report and a comparative review of clinical findings on this condition, focusing on speechlanguage development, cognitive abilities and swallowing evaluation. We suggest that oropharyngeal dysphagia should be further investigated, considering that pulmonary and nutritional disorders affect the survival and quality of life of the patient. As far 
as we know, this is the first study of a patient with partial trisomy $9 \mathrm{p}$ described with oropharyngeal dysphagia.

Key words: Deglutition evaluation; Language evaluation; Deglutition disorders; Language delay; Partial trisomy $9 p$

\section{INTRODUCTION}

Chromosomal structural rearrangements occur in one of every 375 infants. Balanced rearrangements may segregate in the same family, leading to the transmission of unbalanced gametes to future offspring, which results in phenotypic abnormalities caused by duplication or deletion of genetic material (Tihy et al., 2000; Littooij et al., 2002). The phenotype of partial trisomy $9 \mathrm{p}$ includes global developmental delay, microcephaly, bulbous nose, downturned oral commissures, malformed ears, hypotonia, and severe cognitive and language disorders (Sanger et al., 1984; de Pater et al., 2002; Muñoz et al., 2004; Woo et al., 2008). Sporadically, some cases show tumoral manifestations, such as hepatoblastoma (Schnater et al., 2005).

\section{Case report}

The proband was born by uneventful cesarean section after a 39-week gestation. Birth weight was $2390 \mathrm{~g}$, length $46 \mathrm{~cm}(<50$ th percentile), head circumference $43 \mathrm{~cm}(<25$ th percentile), and Apgar scores were 8,10, and 10. Clinical genetic evaluation performed at birth (Figure 1) showed delayed height/weight development, microcephaly, micrognathy, brachycephalic, bulbous nose, downturned oral commissures, malformed ears and feet, and hypotonia, typical features of partial trisomy $9 \mathrm{p}$. These findings were compared to those previously described in the literature (Table 1).
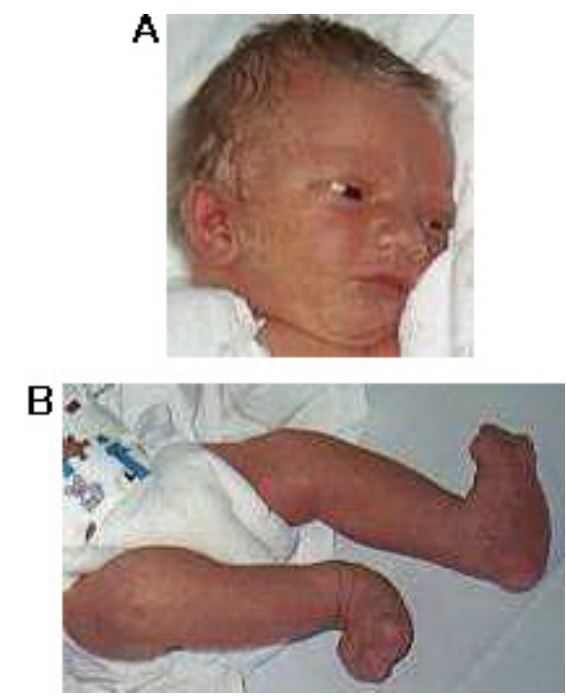

Figure 1. G.A.Z. newly born, at two days of age. Note microcephaly, micrognathy, brachycephalic, bulbous nose, downturned oral commissures, malformed ears (A) and club feet (B). 
Table 1. Clinical signs of the subject cases of trisomy $9 p$ previously reported in the literature.

\begin{tabular}{lcc}
\hline & & \\
& de Pater et al. $(2002)(\mathrm{N}=20)$ & $9 \mathrm{p}$ Trisomy \\
\hline Growth retardation & $10 / 20$ & Our case \\
Low birthweight & $0 / 20$ & + \\
Brachycephaly & $7 / 20$ & + \\
Microcephaly & $8 / 20$ & + \\
Telecanthus & $10 / 20$ & + \\
Enophtalmos & $6 / 20$ & - \\
Antimongoloid slants & $7 / 20$ & + \\
Bulbous nose & $11 / 20$ & + \\
Cleft lip/palate & $2 / 20$ & - \\
Downward oral commissure & $10 / 20$ & + \\
Micro/retrognathy & $7 / 20$ & + \\
Malformed/low-set ears & $13 / 20$ & + \\
Short/webbed neck & $9 / 20$ & + \\
Hand/feet anomalies & $16 / 20$ & + \\
Clinodactyly & $17 / 20$ & + \\
Single palmar crease & $15 / 20$ & + \\
Hypoplastic nails & $7 / 20$ & + \\
Urogenital anomalies & $5 / 20$ & + \\
Cardiac anomalies & $3 / 20$ & + \\
Mental retardation & $19 / 20$ & + \\
Language disorders & $1 / 20$ & + \\
Oropharyngeal dysphagia & $0 / 20$ & + \\
\hline Sign present $(+) ;$; & & + \\
\hline
\end{tabular}

Sign present (+); sign absent (-).

Cytogenetic analysis by means of GTG banding and fluorescence in situ hybridization (FISH) revealed a karyotype of 46,XY der (9) t $(9 ; 15)(9 \mathrm{p} 24 \rightarrow 9 \mathrm{q} 11:: 15 \mathrm{q} 11$. $\rightarrow 15 q 26)$ - 15 (Figure 2a,b).
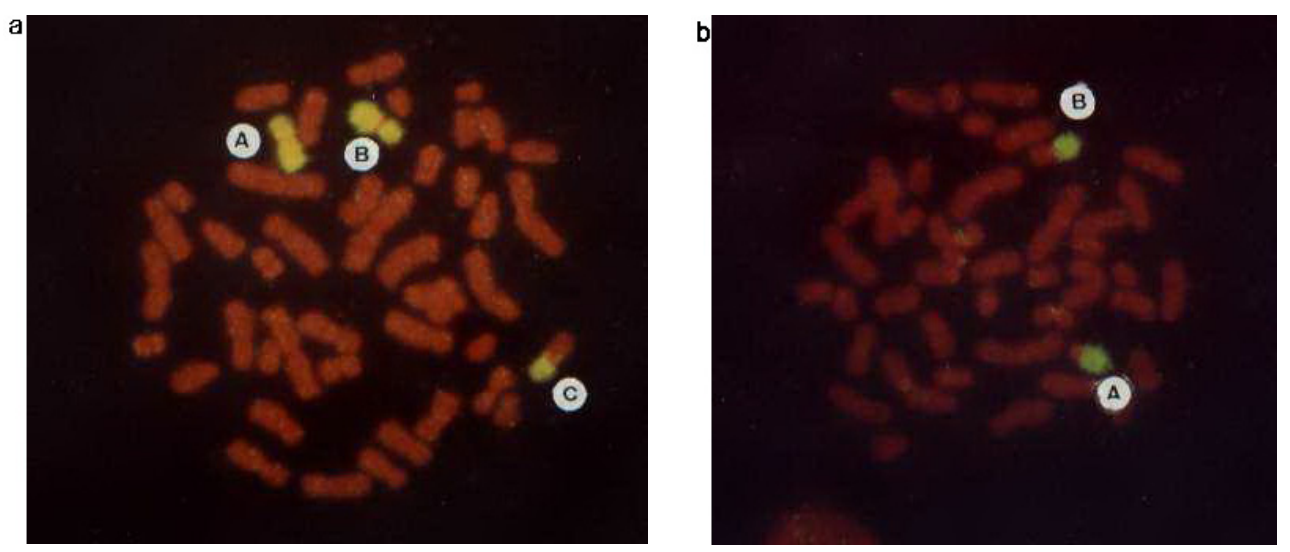

Figure 2. Fluorescence in situ hybridization metaphase following hybridization with total probe chromosomes 9 and $15\left(\mathrm{ONCOR}^{\circledR}\right)$ : a. Normal chromosome 9 (A and B); derivative chromosome 9 with trisomy 9p (C). b. Normal chromosome 15 (A) and derivative chromosome 9 with $\mathrm{t}(9 ; 15)$ (B). 
The proband's brother (IV;1) was also diagnosed with partial trisomy 9p. His medical records included microcephaly, hypertelorism, low-set ears, bilateral epicanthic fold, micrognathy, high hard palate, umbilical hernia, complete transverse palmar crease on his right hand, bilateral clinodactyly of the 5th finger, nail hypoplasia on fingers and toes, and dorsal flexion of the halluces. This infant died at the age of four months due to general systemic complications not described in detail by our source. Individuals III;3 and III;4 were not available for clinical and cytogenetic investigation but had a history of mental retardation and multiple malformations (Figure 3).

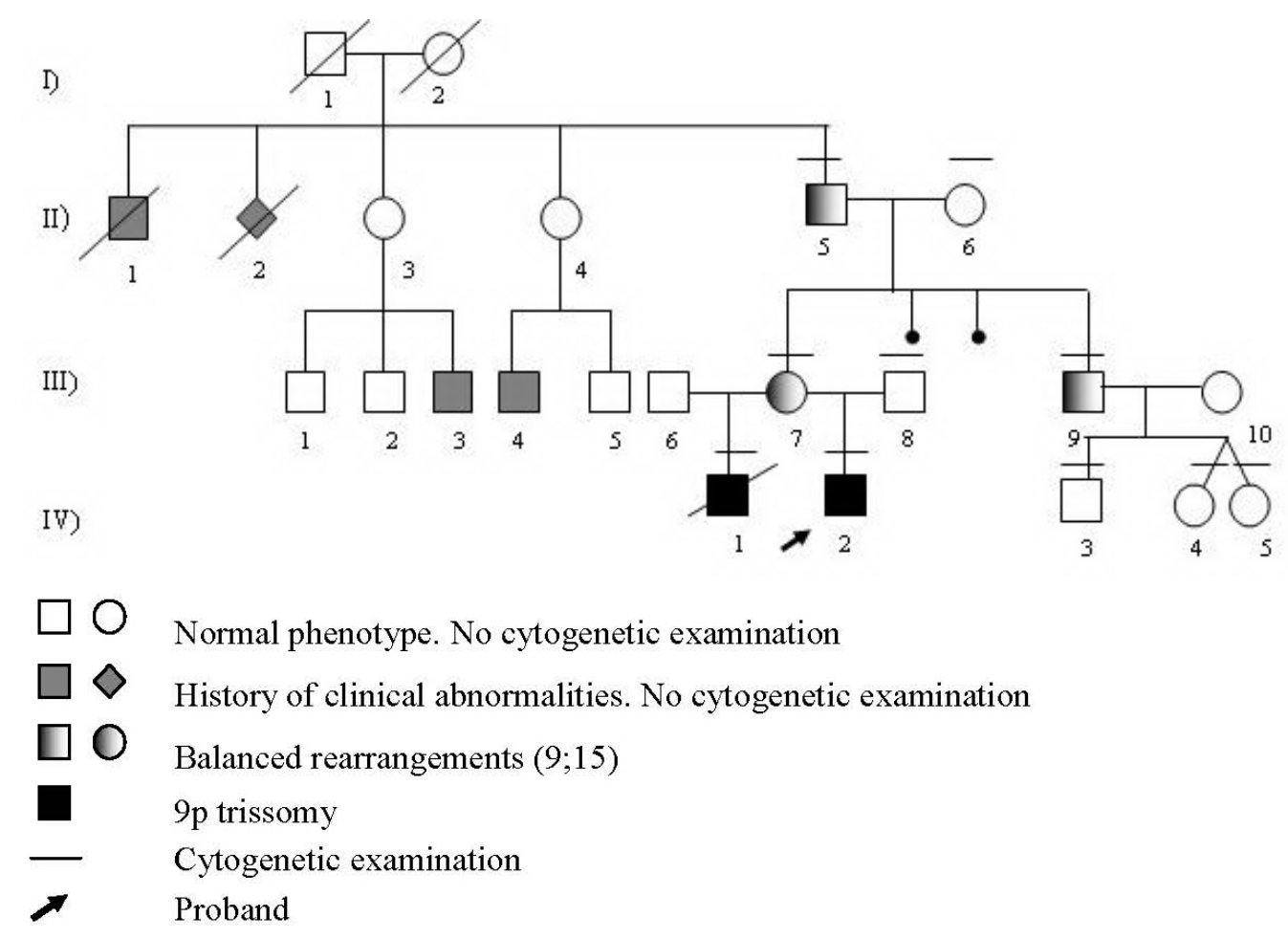

Figure 3. Pedigree of the patient with partial trisomy $9 p$.

\section{Speech-language evaluation}

Evaluation was performed at the age of five months. The Portage Guide was used to assess language abilities, and auditory and visual perceptions (Williams and Aiello, 2001). The patient exhibited cochleopalpebral reflex, reduced ability to perceive information contained in auditory stimuli, and impaired speech perception and sound localization. He did not respond to visual, auditory or sensory stimuli presented from either side of the body, showing poor motor skills. Language assessment revealed delayed onset of pre-speech behaviors, such as smiling and looking with communicative intent as well as babbling, which are expected at five months. Expressive language was significantly affected in the proband, who used crying as a way to communicate. 


\section{Swallowing evaluation}

The patient displayed difficulty swallowing liquids, choking, nasal escape of food, apnea, and recurrent pneumonia. Clinical evaluation of swallowing revealed respiratory distress and choking while swallowing, which suggest laryngeal penetration and/or aspiration. A videofluoroscopic swallowing study revealed abnormal oral and pharyngeal stages of deglutition, bolus escape due to difficulty in pursing the lips, and escape to the valleculae epiglottica and piriform recess. Such alterations were observed mainly during liquid barium testing (Figure 4A). The deglutition reflex was initiated after the bolus had reached the pyriform recess (Figure 4B).
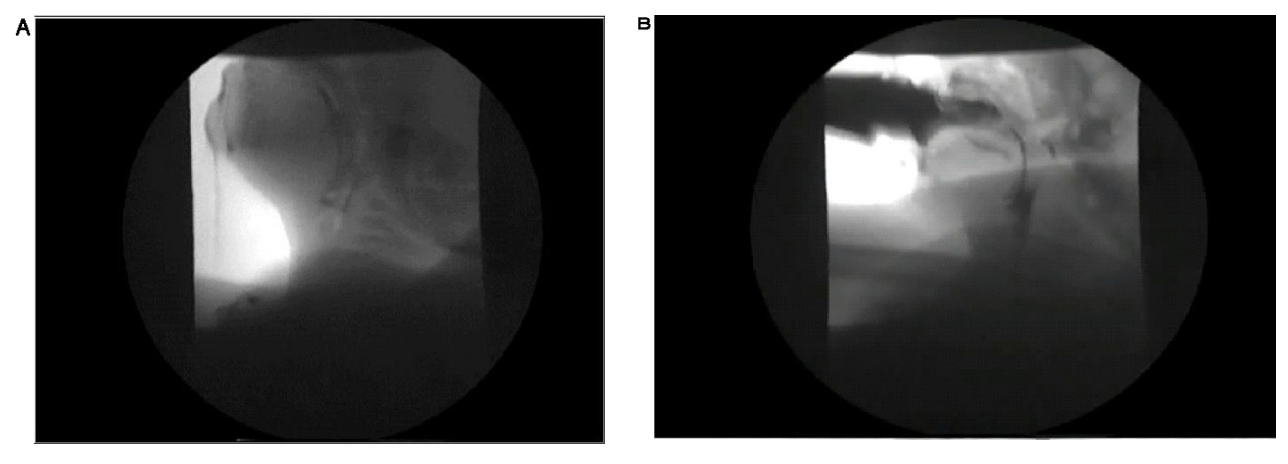

Figure 4. Videofluoroscopic swallowing study during liquid barium testing. Note anterior bolus escape (A) and the deglutition after the bolus had reached the pyriform recess (B).

Head and neck positioning and food consistency variations were tested during the videofluoroscopic swallowing study. These techniques allowed a better oral control minimizing the occurrence of bolus escape and the laryngeal penetration/aspiration risk. Even though the videofluoroscopic swallowing study and clinical swallowing evaluation did not reveal laryngeal penetration or aspiration, the risk of this should be considered, since swallowing mechanism alterations were found.

\section{DISCUSSION}

We describe a family with $9 ; 15$ translocation rearrangements occurring in a balanced form in a grandfather, mother and uncle of the proband, but in an unbalanced form in the proband himself and his brother. The proband manifested typical features of trisomy 9p; the clinical signs were delayed height/weight development, microcephaly, micrognathy, brachycephalic, bulbous nose, downturned oral commissures, malformed ears and feet, and hypotonia (Sanger et al., 1984; de Pater et al., 2002; Muñoz et al., 2004; Woo et al., 2008). These findings were compared to others previously described by de Pater and colleagues in 2002, who reported a similar family, but with an insertion 12;9 translocation occurring in a balanced form in a mother and two sons and in an unbalanced form in the case of the third son, resulting in trisomy of chromosome region 9p22 $\rightarrow$ 9p24. 
The swallowing disorders displayed by our patient characterized oropharyngeal dysphagia. Establishing the diagnosis of this condition was of paramount importance because the symptoms reflected on the patient's overall health, causing recurrent pneumonia and malnutrition. The risk of complications was minimized by the recommendation of nasogastric tube feeding combined with partial oral feeding with volume control, and changes in both food consistency and posture.

In summary, the clinical signs displayed by the patient were consistent with those reported by de Pater et al., in 2002 (Table 1), with the exception of dysphagia, which was not included in the clinical synopsis of the 20 previously described cases. Speech-language evaluation identified several manifestations that are significant in the characterization of the clinical spectrum of this genetic condition. These manifestations should be further investigated, especially those related to swallowing, since pulmonary and nutritional problems can affect the survival of patients with partial trisomy $9 \mathrm{p}$ as well as their quality of life.

\section{REFERENCES}

de Pater JM, Ippel PF, van Dam WM, Loneus WH, et al. (2002). Characterization of partial trisomy 9p due to insertional translocation by chromosomal (micro) FISH. Clin. Genet. 62: 482-487.

Littooij AS, Hochstenbach R, Sinke RJ, van Tintelen P, et al. (2002). Two cases with partial trisomy 9p: molecular cytogenetic characterization and clinical follow-up. Am. J. Med. Genet. 109: 125-132.

Muñoz MSR, Fernández JLH, Puente AT, Manjón-Cabeza AR, et al. (2004). [Trisomía 9p]. Trisomy 9p. Report of two new cases. An. Pediatr. 61: 336-339.

Sanger DD, Stick SL, Sanger WG and Dawson K (1984). Specific syndromes and associated communication disorders: a review. J. Commun. Disord. 17: 385-405.

Schnater JM, Schouten-van Meeteren AY, Heins YM and Aronson DC (2005). Hepatoblastoma in a patient with a partial trisomy 9p syndrome: a case report. Cancer Genet. Cytogenet. 156: 77-79.

Tihy F, Lemyre E, Dallaire L and Lemieux N (2000). Supernumerary chromosome inherited from a maternal balanced translocation leading to pure trisomy 9p. Am. J. Med. Genet. 91: 383-386.

Williams LCA and Aiello AL (2001). O Inventário Portage Operacionalizado: Intervenção com Famílias. Vol. 1. Memnom Edições Científicas, São Paulo.

Woo KS, Kim KE, Kwon EY, Kim JP, et al. (2008). A case of partial trisomy 9pter $\rightarrow$ q13 due to paternal balanced translocation t (9;21) (q13;q21). Korean J. Lab. Med. 28: 155-159. 